Illinois State University

ISU ReD: Research and eData

Theses and Dissertations

2-15-2017

\title{
Effectiveness Of Intuitive Eating Intervention Through A Text Messaging Program Among College Students
}

Tessa J. Loughran

Illinois State University, tspinel@ilstu.edu

Follow this and additional works at: https://ir.library.illinoisstate.edu/etd

Part of the Human and Clinical Nutrition Commons

\section{Recommended Citation}

Loughran, Tessa J., "Effectiveness Of Intuitive Eating Intervention Through A Text Messaging Program Among College Students" (2017). Theses and Dissertations. 762.

https://ir.library.illinoisstate.edu/etd/762

This Thesis is brought to you for free and open access by ISU ReD: Research and eData. It has been accepted for inclusion in Theses and Dissertations by an authorized administrator of ISU ReD: Research and eData. For more information, please contact ISUReD@ilstu.edu. 


\title{
EFFECTIVENESS OF INTUITIVE EATING INTERVENTION THROUGH A TEXT MESSAGING PROGRAM AMONG COLLEGE STUDENTS
}

\author{
Tessa J. Loughran
}

\section{Pages}

A critical time period to prevent overweight may be the college age years. College students experience newfound food independence, possibly resulting in the formation of poor eating habits, such as overeating, or binge eating, placing them at high risk for obesity. Additionally, college students with high perceived stress levels are more likely to experience emotional eating, which may lead to weight gain. Intuitive Eating (IE) practice focuses on listening to the hunger and satiety signals, in hopes that it will prevent overeating, resulting in weight loss. Recently, texting intervention has been seen to be a successful intervention platform for behavior change and nutrition education. Therefore, reaching college students through a text messaging platform may increase the success and adherence to IE guidelines. This study examines if IE through text messaging influences the IE habits, perceived stress, and perceived self-efficacy of college students in comparison to an electronically emailed handout with the same information. Midwestern college students $(n=300)$ completed a pre-survey online which assessed: IE practice (Intuitive Eating Scale), perceived stress (Perceived Stress Scale), and selfefficacy (General Self-Efficacy Scale and Eating Habits Confidence Survey). Participants were then randomly divided into the control $(\mathrm{n}=150)$ or intervention $(\mathrm{n}=150)$ group. The intervention group received five weeks of intervention with weekly IE texts, and the control received the same information in an emailed handout. After intervention was complete, participants took a post-survey, which reassessed participants by the same measures used in the pre-survey. Descriptive statistics were calculated for participant characteristics and variables of interest. 
Control and intervention groups' pre- and post-intervention IE, Perceived Stress, General SelfEfficacy, and Eating Habits Confidence were compared with paired t-tests to assess if the intervention program was associated with significant change in these variables. Additionally, linear regression was used to assess if change in Eating Habits Confidence and Perceived Stress was associated with the IE intervention. A total of 146 (99 intervention, 47 control) participants fully completed the survey, and the majority of participants were 18 years of age $(70 \%)$, white (90\%), female (85\%), freshman in college (75\%), and currently unemployed (75\%). The results of this study found IE texting intervention to significantly increase total IE habits within the college student population. Additionally, IE texting was found increase GSE scores and limit increase PSS levels. The results of this study provide evidence that texting can be a successful platform for increasing IE behaviors among college students.

KEYWORDS: Intuitive Eating, Mindful Eating, Nutrition, Perceived Stress, Self-Efficacy, Texting Intervention 


\title{
EFFECTIVENESS OF INTUITIVE EATING INTERVENTION THROUGH A TEXT \\ MESSAGING PROGRAM AMONG COLLEGE STUDENTS
}

TESSA J. LOUGHRAN

\author{
A Thesis Submitted in Partial \\ Fulfillment of the Requirements \\ for the Degree of \\ MASTER OF SCIENCE \\ Department of Family and Consumer Sciences \\ ILLINOIS STATE UNIVERSITY
}


(C) 2017 Tessa J. Loughran 


\section{EFFECTIVENESS OF INTUITIVE EATING INTERVENTION THROUGH A TEXT MESSAGING PROGRAM AMONG COLLEGE STUDENTS}

TESSA J. LOUGHRAN

COMMITTEE MEMBERS:

Tammy Harpel, Chair

Rachel Vollmer

Julie Schumacher 


\section{ACKNOWLEDGMENTS}

I would like to thank my husband, family, and friends for their unconditional support throughout graduate school. The support you all provided throughout my college career was essential to my success and really pushed me to achieve my goals and aspirations. I would also like to thank my professors for their invaluable guidance and support through my research

process. Designing my own intervention study and writing my thesis would not have been possible without the expertise of my committee members. My research and statistical analysis capabilities have far exceeded than what I thought possible, and I have learned a tremendous amount about the academic research process. 


\section{CONTENTS}

Page

ACKNOWLEDGMENTS

$\begin{array}{lll}\text { CONTENTS } & \text { ii }\end{array}$

TABLES

CHAPTER

I. EFFECTIVENESS OF INTUITIVE EATING INTERVENTION THROUGH A TEXT MESSAGING PROGRAM AMONG COLLEGE STUDENTS 1

Introduction 1

Methodology 3

Participants and Recruitment 3

Procedure 3

Intervention Program 4

Measures $\quad 5$

Data Analysis $\quad 7$

$\begin{array}{ll}\text { Results } & 7\end{array}$

$\begin{array}{ll}\text { Participants } & 7\end{array}$

IES Pre- and Post-Test Score Means Within Groups 8

PSS Pre- and Post-Test Score Means Within Groups 8

EHCS and GSE Pre- and Post-Test Score Means Within Groups 9

Intervention Effects on IE 9

$\begin{array}{ll}\text { Intervention Effects on Self-Efficacy } & 10\end{array}$

$\begin{array}{ll}\text { Intervention Effects on Perceived Stress } & 10\end{array}$

Discussion 11

Conclusion $\quad 15$

$\begin{array}{ll}\text { References } & 23\end{array}$ 
Diet Quality in the US 26

$\begin{array}{ll}\text { Intuitive Eating } & 27\end{array}$

Mindful Eating versus IE 27

IE and Body Mass Index (BMI) and Weight Loss 28

Health Benefits of IE $\quad 29$

IE Practice and Stress Levels $\quad 29$

Self-Efficacy and Adherence to IE practice 30

Texting Intervention Programs 31

References $\quad 35$

APPENDIX A: HEALTHY EATING BEHAVIORS HANDOUT 39

APPENDIX B: RECRUITMENT EMAIL $\quad 40$

APPENDIX C: INFORMED CONSENT 41 


\section{TABLES}

Table

Page

1. Intuitive Eating Principles Descriptions 17

2. Intuitive Eating Texts 18

3. Intuitive Eating Intervention Means and Paired Sample T-Test Results 19

4. Intervention Effects on IE 20

5. Intervention Effects on EHCS 21

6. Intervention Effects on PSS 22 


\section{CHAPTER I}

\section{EFFECTIVENESS OF INTUITIVE EATING INTERVENTION THROUGH A TEXT MESSAGING PROGRAM AMONG COLLEGE STUDENTS}

\section{Introduction}

The prevalence of obesity and overweight among adults in the United States is alarming, with more than one-third of Americans obese and more than two-thirds of Americans overweight (Ogden, Carroll, Kit, \& Flegal, 2014). Overweight and obese adults are at high risk for developing a number of health complications such as type II diabetes, cardiovascular disease, and some types of cancers (Hruby et al., 2016). A critical time period to prevent overweight may be the college age years, because college students experience newfound food independence, possibly resulting in the formation of poor eating habits, such as overeating, or binge eating, placing them at high risk for obesity (Kelly-Weeder, Phillips, Leonard, \& Veroneau, 2014; Smith-Jackson \& Reel, 2012). Additionally, college students with high perceived stress levels are more likely to experience emotional eating, which may lead to weight gain (Wilson, Darling, Fahrenkamp, D'Auria, \& Sato, 2015).

To combat weight gain, the most common form of weight loss intervention used is calorie restriction, but this weight loss method is short-term, often resulting in the regaining of the lost weight (Mann et al., 2007). Recently, intuitive eating (IE) has gained recognition as a successful weight loss intervention method. IE can be defined by three main principles: (a) eating for the purpose of providing the body with energy, not due to emotional cues, (b) listening to the body's hunger and satiety signals, and (c) unconditional permission to eat (Mathieu, 2009). The use of IE methods in college students has been associated with weight loss, lower blood lipid levels, and improved cardiovascular risk (Hawks, Madanat, Hawks, \& Harris, 2005). 
Text messaging intervention programs may be an appropriate platform for changing health behaviors among college students because these programs have been described as effortless, but effective due to the automated text message reminders (Obermayer, Riley, Asif, \& Jean-Mary, 2004). One pilot texting program for MyPlate nutrition education found that participants had a better understanding of the MyPlate guidelines and an increased fruit consumption in comparison to the control group that received a mailed brochure containing the same information (Brown, O'Connor, and Salvaiano, 2014). These results suggest that a text messaging IE nutrition intervention may be an effective, efficient way to reach the college population in order to prevent excessive weight gain.

Currently, to the authors' knowledge, no studies have evaluated the success and overall effectiveness of using text messaging as a platform for IE intervention to combat obesogenic behaviors among college students. Compared to traditional intervention methods, reaching college students through a text messaging platform may increase the success and adherence to IE guidelines, in a relatively cost-effective manner. In turn, increased adherence to IE methods may promote healthy eating habits in college students, decreasing the overall risk for excessive weight gain. The results of this study can help determine if IE intervention through text messaging can improve eating habits and provide evidence that text messaging is a successful platform for IE intervention in the college student population.

The research questions investigated included: (a) Does intuitive eating intervention through text messaging influence the overall intuitive eating habits of college students in comparison to an electronically emailed handout with the same information? (b) Does intuitive eating intervention through text messaging influence college students' perceived self-efficacy in relation to diet in comparison to an electronically emailed handout with the same information? 
and (c) Does intuitive eating intervention through text messaging affect college students' perceived stress in comparison to an electronically emailed handout with the same information?

\section{Methodology}

\section{Participants and Recruitment}

This study was approved by Illinois State University's Institutional Review Board. Potential participants were identified and contacted through the University's listserv of students who have indicated they were willing to receive emails regarding student research. Inclusion criteria included: (1) Illinois State University students 18 to 24 years of age, (2) must have a personal smartphone and be able to receive standard text messages, and (3) live within a 15minute walking distance to campus. No exclusion criteria existed for gender, race, ethnicity, or income level. The goal sample size was 300 participants, which was randomly divided into the control $(\mathrm{n}=150)$ and intervention $(\mathrm{n}=150)$ group. Cell phone numbers and email addresses were obtained from participants once they consented to participate.

\section{Procedure}

Informed consent was obtained from each participant using the online platform Select Survey. Following consent, participants completed several questionnaires, including the Intuitive Eating Scale (IES), Perceived Stress Scale (PSS), the General Self-Efficacy Scale (GSE), and the Eating Habits Confidence Survey, all via Select Survey. From the time the initial recruitment email was sent, participants had two weeks to volunteer for the study and complete the preintervention surveys. A reminder email was sent one week after the initial recruitment email was sent. It was estimated that the online surveys would take each participant approximately 15 to 30 minutes for completion. 
Once the pre-intervention surveys were completed and cell phone numbers and email addresses were obtained, 150 participants were randomly assigned to the texting intervention group, and 150 participants were randomly assigned to the control group. The control group received a general Healthy Eating Behaviors intervention email one week after the preintervention survey closed. The intervention group began the Healthy Eating Behaviors Text Messaging Program one week after the pre-intervention survey closed.

Intervention program. The texting program was five weeks long and consisted of a total of 10 text messages, at a rate of two each week (Table 2). Text messages, based off of the 10 IE principles, were constructed in 160 characters or less. The text messages were sent to participants through mass text messaging provider, EZ Texting. The texts were sent Monday through Saturday, at either 11:00am or 5:00pm CST. Participants in the intervention group were able to opt out of the study at any time by texting STOP.

The control group received the same messages as the texting intervention group, however, all the messages were delivered at one time as a PDF handout through email. They were able to reply "STOP" by email at any time to withdraw from the study. See appendix A for the complete PDF.

After five weeks, the intervention portion of the study was completed. The week after the intervention was completed, both intervention and control participants were sent an email with a link to take the post-intervention survey which was administered via Select Survey. Once the post-intervention survey was complete, participants were able to click a link that redirected them to a separate webpage in which they could provide their name, email address, and mailing address to enter themselves into a random drawing for one of four $\$ 25$ gift cards. 


\section{Measures}

The online pre-intervention survey measured intuitive eating behaviors, perceived stress, general self-efficacy, and self-efficacy related to diet. Additionally, participants answered demographic questions (age, gender, year in college, ethnicity, distance from school, and employment) and reported height and weight (which were used to calculate BMI). The online post-intervention survey contained all of the measures used during the pre-intervention survey, except for demographic-related questions that were likely not to change during the intervention period.

The Intuitive Eating Scale-2 (IES) is a 23-item measure that assesses the participants' eating habits and use of IE (Tylka \& Kroon, 2013). The IES has four subscales, which include unconditional permission to eat, eating for physical rather than emotional reasons, reliance on hunger and satiety cues, and body-food choice congruence. The questionnaire uses a 5-point Likert scale ( 1 = strongly disagree, 5 =strongly agree). Each of the four subscales are scored by averaging each subset of questions in each subscale. Total IES is scored by averaging all items. The average IES scores may range from one to five, with five indicating high intuitive eating practice. The Intuitive Eating Scale has been found to be reliable and validated for the undergraduate college student population (Tylka \& Kroon, 2013). The scales showed high levels of reliability for this study based on Cronbach's alpha scores for the pre-intervention survey (.813) and post-intervention survey (.849).

Perceived stress was measured by the Perceived Stress Scale (PSS) (Cohen, Bruner, Kuryluk, \& Whitton, 2015). The Perceived Stress Scale (PSS) is a 10-item questionnaire that evaluates participants' stress levels in relation to their feelings within the past month using a 4point scale $(0=$ never, $4=$ very often $)$. The items of this scale are summed, with scores ranging 
from 0 to 40, and a higher score indicating a higher perceived stress level (Cohen, Bruner, Kuryluk, \& Whitton, 2015). This scale has been found to have considerable reliability and validity when used within the college population to assess perceived stress levels (Cohen, Kamarck, \& Mermelstein,1983). The scales used for this study showed high levels of reliability based on Cronbach's alpha scores for the pre-intervention survey (.877) and post-intervention survey (.892).

The Eating Habits Confidence Survey (EHCS) was used to evaluate how confident a participant is in accomplishing a certain behavior for the next six months (Sallis, Pinski, Grossman, Patterson, \& Nader, 1988). Ultimately, this helps determine possible behaviors that might occur during dieting. This scale contains 20 items, with four subscales that assess resisting relapse, reducing calorie intake, reducing salt consumption, and reducing fat consumption (Sallis et al., 1988). Using a 5-point Likert scale ( 1 = I know I cannot; 5 = I know I can), participants report how confident they feel that they can accomplish a given eating behavior, with a maximum summed score of 100 points. Greater scores indicate higher selfefficacy levels. This scale has previously been found to be reliable and valid among adult women (Wright Decker, \& Dennis, 2013). The Cronbach's alphas coefficients were adequate for the preintervention survey (.795) and post-intervention survey (.856).

The General Self Efficacy (GSE) questionnaire was used to assess participants' general confidence levels in completing or coping with difficult tasks or issues (Schwarzer \& Jerusalem, 1995). The scale contains 10 items and uses a 4 -point Likert scale ( $1=$ not true at all; $4=$ exactly true). The scores were summed together ranging from 10 to 40, with higher scores indicating greater self-efficacy. This scale was found to be reliable and valid when measuring general selfefficacy in adult individuals aged 18 to 87 years (De las Cuevas, \& Peñate, 2015). The results of 
the Cronbach alpha scores for this survey showed high reliability for the pre-intervention survey (.853) and post-intervention survey (.887).

\section{Data Analysis}

IBM SPSS Statistics Version 24 software was used to analyze the results from the preand post-intervention surveys used in the study. Descriptive statistics were calculated for participant characteristics and variables of interest. To evaluate the effects the intuitive eating texting intervention had on college students' overall intuitive eating habits, perceived stress, and diet self-efficacy in comparison to the control, paired $t$-tests were used with a significance value of $\mathrm{p}<0.05$. Control and intervention groups' pre- and post-intervention Intuitive Eating, Perceived Stress, General Self-Efficacy, and Eating Habits Confidence were compared with paired $t$-tests to assess if the intervention program was associated with significant change in these variables. Additionally, linear regression was used to assess if change in Eating Habits Confidence and Perceived Stress was associated with the intuitive eating intervention. In each regression, participant change in BMI, race, gender, and ethnicity were entered as covariates and pre-intervention scores were used as control variables in the equation.

\section{Results}

\section{Participants}

A total of 6,035 students, between the ages of 18 to 24 years, were recruited for the study. For the pre-intervention survey, 526 individuals opened the survey, 412 consented to participate, and 300 fully completed the survey. Individuals who completed the survey were then randomly assigned to the intervention or control group. Eight participants in the intervention texting group replied "STOP" and opted out of the study, while one participant in the email control group replied "STOP" and opted out of the study. 
After the five-week intervention was completed, 227 participants opened the postintervention survey, and 146 (99 intervention, 47 control) fully completed the survey. Of the 146 participants who fully completed both the pre-intervention and post-intervention surveys, the majority of participants were 18 years of age $(70 \%)$, white $(90 \%)$, female $(85 \%)$, freshman in college $(75 \%)$, and currently unemployed (75\%).

\section{IES Pre- and Post-Test Score Means Within Groups}

Mean IES scores were calculated for both the control and intervention groups. Table 3 shows the pre-intervention survey and post-intervention survey means for both groups, as well as changes between the means. Within the intervention group, scores for the IES total score significantly increased by $.096, t(98)=2.564, p<.05$. Additionally, for the intervention group, change in one of the four subscales within the IES scale, Reliance on Hunger and Satiety Cues, was found to be significant. The subscale Reliance on Hunger and Satiety Cues significantly increased by $.201, t(98)=2.866, p<.005$. Both of these significant findings within the intervention group show an increase in intuitive eating behavior, post-intervention. Changes within the intervention group for IES scores were significant; however, within the control group, there were no significant differences found between the pre-intervention survey and postintervention survey IES scores.

\section{PSS Pre- and Post-Test Score Means Within Groups}

Mean PSS scores were calculated for both the control and intervention groups. Table 3 shows the pre-intervention survey and post-intervention survey means for both groups, as well as changes between the means. Scores significantly increased by 1.303 for PSS scores, $t(98)=$ $2.214, p<.05$, among the intervention group, indicating an increase in perceived stress from preto post-intervention. In addition, it should be noted that the PSS scores increased for both the 
intervention and the control groups. The control group had a non-significant increase in PSS scores of $1.660, t(46)=1.926, p>.05$, and the intervention group had a significant increase of 1.303. Although perceived stress increased in both groups, the control group post-intervention score was higher than the intervention group post-intervention score. Therefore, the control group had a greater increase in perceived stress than the intervention group.

\section{EHCS and GSE Pre- and Post-Test Score Means Within Groups}

Mean GSE and EHCS scores were calculated for both the control and intervention groups. Table 3 shows the pre-intervention survey and post-intervention survey means for both groups, as well as changes between the means. Although the results were not statistically significant, the results indicated an increase in both EHCS and GSE scores for the intervention group. Average EHCS scores increased by .333 and GSE scores increased by .534, indicating both perceived self-efficacy and perceived diet-efficacy increased from pre- to post-intervention. Among the control group, GSE scores decreased by -.987 , while EHCS scores increased by 1.617. However, it should be noted that the control group had a greater increase in EHCS scores than the intervention group.

\section{Intervention Effects on IE}

Linear regression was used to assess if IE intervention was associated with change in IES scores. Participants' change in BMI, age, gender, year in college, and race were entered as covariates in the regression model, with the IE pre-intervention survey score used as a control variable.

The regression model, excluding the independent variable (IE intervention), was statistically significant, $R^{2}=.528, F(6,139)=25.093, p<.0005$. Pre-intervention IES survey scores were significantly correlated with post-intervention IES scores. The pre-intervention 
survey scores remained significantly correlated after the independent variable was added to the model; however, the independent variable was not significantly related to IES post-intervention survey scores. See Table 4 for detailed regression results. Therefore, the results of the full regression analysis indicated IE texting intervention did not relate to post-intervention survey IES scores.

\section{Intervention Effects on Self-Efficacy}

In addition, a linear regression was used to assess if IE intervention was associated with change in EHCS scores among groups. Participants' change in BMI, age, gender, year in college, and race were also entered as covariates in the regression model. The pre-intervention EHCS survey score used as a control variable.

The results of the regression model, when excluding the independent variable, (IE intervention) was statistically significant, $R^{2}=.327, F(6,139)=11.234, p<.0005$. Preintervention EHCS survey scores were significantly correlated with post-intervention EHCS scores. The pre-intervention survey scores remained significantly correlated after the independent variable was added to the model; however, the independent variable was not significantly associated with EHCS post-intervention survey scores. See Table 5 for full details on this regression. Thus, the results of the full regression analysis indicated IE texting intervention did correlate with post-intervention survey EHCS scores.

\section{Intervention Effects on Perceived Stress}

Finally, linear regression was used to assess if IE intervention was associated with change in PSS scores among groups. Participant change in BMI, age, gender, year in college, and race were entered as covariates in the model, with the pre-intervention PSS survey entered as a control variable. 
The results of the regression model, without the independent variable included (IE intervention), were statistically significant, $\mathrm{R}^{2}=.414, \mathrm{~F}(6,139)=16.394, \mathrm{p}<.0005$. Preintervention PSS survey scores were significantly associated with post-intervention PSS scores. The pre-intervention survey scores remained significantly associated after the independent variable was added to the model; however, the independent variable did not result in a significant relationship between PSS post-intervention survey scores. See Table 6 for full details on this regression. Thus, the results of the full regression analysis indicated the IE texting intervention was not associated with post-intervention survey PSS scores.

\section{Discussion}

This study examined the effectiveness of an intuitive eating texting program in comparison to an emailed handout within the college student population. The intervention effects

on IE practice, eating habit confidence, and perceived stress levels were examined. The results of this study showed significant increases in total IES scores within the intervention group, with greater changes for the intervention group than the control group. These findings suggest that IE texting intervention over a five-week period may be more effective in improving IE practice than receiving an emailed IE handout. A similar study also found increases in targeted nutrition related behaviors and knowledge when evaluating the effectiveness of a nutrition education based texting program, Mobile MyPlate (Brown et al., 2014). Once Mobile MyPlate intervention was complete, results showed increases in fruit consumption and MyPlate nutrition knowledge when compared to the control (a mailed handout with the same information). The success of Mobile MyPlate and the IE texting program both suggest texting intervention programs can increase desired nutrition related behaviors more than a handout delivered at a single time. 
In addition to the significant increase in total IES scores, the IES subscale Reliance on Hunger and Satiety Cue scores significantly increased among the intervention group. This finding may suggest that texting IE reminders are an effective way to remind individuals of their hunger and satiety cues, versus reading this within an emailed handout. Interestingly, this subscale actually decreased in the control group. This finding may be explained by the timeliness of the texts sent in the intervention. The texts for this study were purposely sent slightly before meal times, with the intention of reminding participants to focus on their IE skills before consuming meals. Having texts sent before meal times may have been more successful at increasing IE behavior than the emailed handout because participants did not have to motivate themselves to reference the handout at meal time. This finding is consistent with the study completed by Obermayer et al. (2004) which showed a texting smoking cessation program was successful because participants did not have to seek information (i.e., open an email, log into a website). The results of our study, and previous similar studies, suggest that texting programs may increase desired behaviors due to the text timing and the minimal effort needed to seek information that may promote the targeted behavior.

The current findings showed the intervention group reported significantly higher PSS scores in the PSS post-survey. The results for the control group's average PSS scores were not significant, however, it should be noted the texting intervention group had a smaller amount of change and lower levels in perceived stress after the intervention was completed in comparison to the control group. This finding may suggest that an IE texting intervention may have a greater impact on helping one to manage their perceived stress level than information that is delivered one time via email. Yet, both intervention and control PSS scores increased from pre- to postintervention. The increases in scores may be attributed to the environment of the population. The 
majority of the students who participated in this study were freshman (75\%). In addition, this study took place during the first semester of college, which can be a very stressful time for students, due to the adjustment of being away from home and course workload. Students are also experiencing newfound food independence, which can create poor eating habits, such as overeating, or binge eating (Kelly-Weeder, Phillips, Leonard, \& Veroneau, 2014; Smith-Jackson \& Reel, 2012). Also, college students with high perceived stress levels are more likely to experience emotional eating (Wilson, Darling, Fahrenkamp, D'Auria, \& Sato, 2015). Emotional eating and poor eating habits due to the new college setting may be related to high levels of perceived stress, possibly altering PSS scores. Our results may further be explained by a study that examined the relationship between IE and perceived stress among Finnish obese adults (Järvelä-Reijonen et. al, 2016). This study found increased amounts of perceived stress correlated with low IE practice. Our IE texting intervention made a slight impact on PSS scores among the intervention group; however, the IE texting intervention may have had a larger impact in a less stressful context. Further studies need to be completed to examine the relationship of IE intervention and its effect on PSS levels.

Results of the GSE scores and EHCS scores among both groups were not significant, in contrast to previous research. Annessi and Gorjala (2010) found increases in self-efficacy were related to increases in desired health behaviors and outcomes among an adult population, when a six6-month intervention program was implemented that involved nutrition and exercise treatment. Our study did not provide evidence IE intervention correlated with increased selfefficacy. It is possible that our IE texting program could have resulted in increases in selfefficacy if the intervention program was longer-term, such as the Annessi and Gorjala (2010) 
intervention, versus only five weeks in duration. Further studies should utilize longer interventions to further examine this relationship.

Although the results were not statistically significant for GSE, the GSE scores among the control group decreased, while the intervention group GSE scores increased. These results may be explained by the relationship between GSE and PSS. As previously stated, the intervention group reported a smaller increase in PSS when compared to the control group. Moeini et al. (2008) conducted a study examining the relationship between PSS and GSE levels in Iranian Male high school students. The study found that increased amounts of PSS lead to decreased amounts of GSE (Moeini et al. 2008). Since PSS levels showed a greater increase among the control group when compared to intervention group scores, this may explain why GSE scores decreased in the control and increased in the intervention. However, these results were not significant, and the relationship between GSE, PSS, and IE intervention needs to be examined further.

There are several limitations to this study that should be discussed. First, it is unknown if the participants opened the text messages and, if they did, how they used the texts. It may be that the intervention group participants did not receive the full benefits of the texts. In support of this, other successful studies have included interaction via text between participants and researchers (de Niet et al., 2012; Bauer, de Niet, Timman, \& Kordy, 2010). Having interaction with participants may help monitor and encourage participant engagement and may also increase intervention effectiveness. Future research would benefit from including a mechanism that motivates participants to open and read the text messages.

Attrition was an issue in this study. Some participants who completed survey 1 did not complete survey 2 , resulting in more participants within the intervention group and only 47 
participants in the email (control) group. Variances between group sizes may have produced unbalanced results. These varied group sizes may, at least in part, be due to the intervention group receiving a reminder text to complete the survey, while the control received an email, not a text. Other studies have found texting to be a better form of communication than emailing or mail for the college-aged population due to automated text message reminders, instead of having to motivate themselves to seek information by opening an email or logging into a website (Brown, O’Connor, \& Salvaiano, 2014; Hebden et al., 2014; Obermayer, Riley, Asif, \& JeanMary, 2004;). The likelihood of attrition may be decreased in future studies through the use of texting reminders for both groups.

Additionally, all data in this study were self-reported by participants. Questions related to food behaviors, stress levels, and weight may have made some participants feel uncomfortable, and participants may not have answered honestly. Given that screening of participants and their knowledge of IE prior to this study was not assessed, it is unknown if participants were ever exposed to IE or had knowledge of IE prior to this study. Pre-existing knowledge and use of IE prior to the study may have affected the degree of change in scores.

\section{Conclusion}

Previous research suggested texting programs are effective for delivery of nutrition related information; however, this study was the first to implement IE education in a texting platform. The results of this study found IE texting intervention to significantly increase total intuitive eating habits within the college student population. Additionally, IE texting was found to be associated with increases GSE scores and limited increases in PSS levels. The results of this study provide evidence that texting can be a successful platform for increasing IE behaviors 
among college students. Implementing IE eating texting programs on college campuses can increase student healthy eat habits, which may reduce obesity and promote healthy lifestyles. 
Table 1

Intuitive Eating Principles Descriptions

\begin{tabular}{|c|c|}
\hline IE Principles & Description \\
\hline Principle 1 & $\begin{array}{l}\text { Reject the diet mentality: Ignore magazine articles and diet books that provide } \\
\text { short-term weight loss. Give all of your attention to IE methods. }\end{array}$ \\
\hline Principle 2 & $\begin{array}{l}\text { Honor your hunger: Prevent excessive hunger and rebuild trust with yourself } \\
\text { and food. }\end{array}$ \\
\hline Principle 3 & $\begin{array}{l}\text { Make peace with food: Give yourself unconditional permission to eat. Do not } \\
\text { deprive yourself in order to prevent uncontrollable cravings and binges. }\end{array}$ \\
\hline Principle 4 & Challenge the food police: There are no "good" or "bad foods". \\
\hline Principle 5 & Feel your fullness: Listen to the internal body signals of hunger and fullness. \\
\hline Principle 6 & $\begin{array}{l}\text { Discover the satisfaction factor: Eating foods that you like, in a comfortable } \\
\text { environment, allowing you to feel satisfied. }\end{array}$ \\
\hline Principle 7 & $\begin{array}{l}\text { Cope with your emotions without using food: Resolve emotional issues without } \\
\text { using food. }\end{array}$ \\
\hline Principle 8 & $\begin{array}{l}\text { Respect your body: Do not be overly critical or unrealistic of your body type } \\
\text { and genetic makeup. }\end{array}$ \\
\hline Principle 9 & $\begin{array}{l}\text { Exercise - feel the difference: Participate in activities that promote exercise that } \\
\text { you enjoy. }\end{array}$ \\
\hline Principle 10 & $\begin{array}{l}\text { Honor your health - general nutrition: Choose foods that are good for your } \\
\text { health and that you enjoy the taste of. }\end{array}$ \\
\hline
\end{tabular}


Table 2

Intuitive Eating Texts

\begin{tabular}{|c|c|}
\hline $\begin{array}{l}\text { Text } \\
\text { Message }\end{array}$ & Description \\
\hline 1 & $\begin{array}{l}\text { Forget all methods of dieting today! Focus on listening to what your body is } \\
\text { telling you. }\end{array}$ \\
\hline 2 & $\begin{array}{l}\text { Ask yourself before eating today, is your body telling you it's hungry? You } \\
\text { may be experiencing a behavior or emotion urging you to eat, and no actual } \\
\text { hunger. }\end{array}$ \\
\hline 3 & $\begin{array}{l}\text { Sometimes our bodies crave sweet treats. Remind yourself that it's okay to } \\
\text { enjoy your favorite foods in moderation. }\end{array}$ \\
\hline 4 & Remember: There are no good or bad foods! Aim for a well-balanced diet. \\
\hline 5 & Feel your fullness: Listen to the internal body signals of hunger and fullness. \\
\hline 6 & $\begin{array}{l}\text { Sit down and enjoy your dinner today. Turn off the television and focus on the } \\
\text { meal you're eating without distractions. }\end{array}$ \\
\hline 7 & $\begin{array}{l}\text { Feeling stressed or upset? Eating when you're not hungry won't help you } \\
\text { manage your emotions. }\end{array}$ \\
\hline 8 & $\begin{array}{l}\text { Respect and love yourself. Remember you are different from all others and you } \\
\text { should appreciate your genetic makeup! }\end{array}$ \\
\hline 9 & $\begin{array}{l}\text { Get out and exercise today! Whether it's an extra-long walk or perhaps a new } \\
\text { fitness class at the gym - your body will thank you for it. }\end{array}$ \\
\hline 10 & Honor your health - choose foods that make you feel good and taste good! \\
\hline
\end{tabular}


Table 3

Intuitive Eating Intervention Means and Paired Sample T-Test Results

\begin{tabular}{lcccccc}
\hline & \multicolumn{2}{c}{ Pre-Survey } & \multicolumn{2}{c}{ Post-Survey } & \multicolumn{2}{c}{ Change } \\
Scales & INT & CNT & INT & CNT & INT & CNT \\
\hline IE Total & 3.27 & 3.24 & 3.37 & 3.24 & $.096^{*}$ & .001 \\
Factor $1^{a}$ & 3.01 & 3.06 & 2.97 & 3.05 & -.037 & -.011 \\
Factor $2^{b}$ & 3.21 & 3.06 & 3.32 & 3.10 & .106 & .040 \\
Factor $3^{c}$ & 3.50 & 3.41 & 3.70 & 3.39 & $.201 * *$ & -.011 \\
Factor $4^{d}$ & 3.52 & 3.75 & 3.63 & 3.70 & .114 & -.057 \\
EHCS & 48.06 & 52.30 & 48.39 & 53.92 & .333 & 1.617 \\
GSE & 30.83 & 32.81 & 31.36 & 31.83 & .534 & -.987 \\
PSS & 18.01 & 17.98 & 19.31 & 19.64 & $1.303^{*}$ & 1.660
\end{tabular}

Note. $N=146$. Intervention $N=99$. Control $N=47 * \mathrm{p}<.05, * * \mathrm{p}<.005$.
a. Unconditional permission to eat
b. Eating for physical rather than emotion reasons
c. Reliance on hunger and satiety cues
d. Body-Food Choice Congruence 
Table 4

Intervention Effects on IE

\begin{tabular}{|c|c|c|c|c|}
\hline \multicolumn{5}{|c|}{ Post-Survey IES Scores } \\
\hline \multicolumn{5}{|c|}{ Model 2} \\
\hline Variable & B & Beta & $t$ & $p$ \\
\hline Constant & -.589 & & -.695 & .488 \\
\hline IES Pre-Survey & $.741 * *$ & .683 & 11.423 & .000 \\
\hline Age & .083 & .232 & 1.795 & .075 \\
\hline Race & -.014 & -.019 & -.320 & .750 \\
\hline Year in School & -.100 & -.211 & -1.610 & .110 \\
\hline Gender & -.058 & -.043 & -.720 & .473 \\
\hline Change in BMI & -.043 & -.083 & -1.411 & .160 \\
\hline Program & .097 & .094 & 1.498 & .137 \\
\hline R2 & .528 & & & \\
\hline $\mathrm{F}$ & $22.021 *$ & & & \\
\hline Chang in R2 & .008 & & & \\
\hline Change in $\mathrm{F}$ & 2.243 & & & \\
\hline
\end{tabular}

Note. $N=146 .{ }^{*} \mathrm{p}<.001$. 
Table 5

Intervention Effects on EHCS

\begin{tabular}{|c|c|c|c|c|}
\hline \multicolumn{5}{|c|}{ Post-Survey EHCS Scores } \\
\hline \multicolumn{5}{|c|}{ Model 2} \\
\hline Variable & B & Beta & $t$ & $p$ \\
\hline Constant & 11.450 & & .668 & .505 \\
\hline IES Pre-Survey & $.571 * *$ & .500 & 7.040 & .000 \\
\hline Age & $.661 *$ & .109 & .711 & .478 \\
\hline Race & -1.892 & -.153 & -2.154 & .033 \\
\hline Year in School & -1.530 & -.189 & -1.208 & .229 \\
\hline Gender & 1.554 & .067 & .952 & .343 \\
\hline Change in BMI & -.433 & -.050 & -.707 & .481 \\
\hline Program & -1.528 & -.087 & -1.159 & .248 \\
\hline R2 & .333 & & & \\
\hline $\mathrm{F}$ & $9.844 * *$ & & & \\
\hline Chang in R2 & 2.99 & & & \\
\hline Change in F & 1.343 & & & \\
\hline
\end{tabular}


Table 6

Intervention Effects on PSS

\begin{tabular}{|c|c|c|c|c|}
\hline \multicolumn{5}{|c|}{ Post-Survey PSS Scores } \\
\hline \multicolumn{5}{|c|}{ Model 2} \\
\hline Variable & B & Beta & $t$ & $p$ \\
\hline Constant & 27.060 & & 1.974 & .050 \\
\hline IES Pre-Survey & $.646^{* *}$ & .602 & 9.022 & .000 \\
\hline Age & -1.157 & -.227 & -1.571 & .118 \\
\hline Race & .163 & .016 & .237 & .813 \\
\hline Year in School & 1.328 & .195 & 1.336 & .184 \\
\hline Gender & 2.261 & .117 & 1.764 & .080 \\
\hline Change in BMI & -.321 & -.044 & -.666 & .507 \\
\hline Program & -.410 & -.028 & -.396 & .692 \\
\hline $\mathrm{R} 2$ & .415 & & & \\
\hline $\mathrm{F}$ & 13.989 & & & \\
\hline Chang in R2 & .001 & & & \\
\hline Change in $\mathrm{F}$ & .157 & & & \\
\hline
\end{tabular}




\section{References}

Annesi, J., \& Gorjala, S. (2010). Relations of self-regulation and self-efficacy for exercise and eating and BMI change: A field investigation. Biopsychosocial Medicine, 4(1), 10. doi: $10.1186 / 1751-0759-4-10$

Brown, O. N., O'Connor, L., \& Savaiano, D. (2014). Mobile MyPlate: A pilot study using text messaging to provide nutrition education and promote better dietary choices in college students. Journal of American College Health, 62(5), 320-227. doi:

10.1080/07448481.2014.899233.

Cohen, S., Bruner, M. R., Kuryluk, A. D., \& Whitton, S. W. (2015). Perceived Stress Scale--14. Journal of American College Health, 63(2), 98-108. doi: 10.1517/13543784.12.11.1757

Cohen, S., Kamarck, T., \& Mermelstein, R. (1983). A global measure of perceived stress. Journal of Health and Social Behavior, 24(4), 385-396. Retrieved from http://www.jstor.org/stable/2136404

De las Cuevas, C., \& Peñate, W. (2015). Validation of the General Self-Efficacy Scale in psychiatric outpatient care. Psicothema, 27(4), 410-415. doi:10.7334/psicothema2015.56

de Niet, J., Timman, R., Bauer, S., van den Akker, E., de Klerk, C., Kordy, H., Passchier, J. (2012). Short message service reduces dropout in childhood obesity treatment: A randomized controlled trial. Health Psychology, 31(6), 797-805. doi: 10.1037/a0027498

Hawks, S., Madanat, H., Hawks, J., \& Harris, A. (2005). The relationship between intuitive eating and health indicators among college women. American Journal of Health Education, 36(6), 331-336. doi:10.1080/19325037.2005.10608206

Hebden, L., Cook, A., Ploeg, H. P., King, L., Bauman, A., \& Allman-Farinelli, M. (2014). A mobile health intervention for weight management among young adults: A pilot randomized 
controlled trial. Journal of Human Nutrition \& Dietetics, 27(4), 322-332.

doi:10.1111/jhn. 12155

Hruby, A., Manson, J., Lu, Q., Malik, V., Rimm, E., Qi, S., \& Hu, F. (2016). Determinants and Consequences of Obesity. American Journal of Public Health, 106(9), 1656-1662. doi:10.2105/AJPH.2016.303326

Järvelä-Reijonen, E., Karhunen, L., Sairanen, E., Rantala, S., Laitinen, J., Puttonen, S., \& Kolehmainen, M. (2016). High perceived stress is associated with unfavorable eating behavior in overweight and obese Finns of working age. Appetite, 103, 249-258. doi:10.1016/j.appet.2016.04.023

Kelly-Weeder, S., Phillips, K., Leonard, K., \& Veroneau, M. (2014). Binge eating and weight loss behaviors of overweight and obese college students. Journal of the American Association of Nurse Practitioners, 26(8), 445-451. doi:10.1002/2327-6924.12070

Mann, T., Tomiyama, A. J., Westling, E., Lew, A., Samuels, B., \& Chatman, J. (2007). Medicare's search for effective obesity treatments: Diets are not the answer. American Psychologist, 62(3), 220-233. doi: 10.1037/0003-066X.62.3.220

Mathieu, J. (2009). Practice application: What should you know about mindful and intuitive eating? Journal of the American Dietetic Association, 109(12), 1982-1987. doi: 10.1016/j.jada.2009.10.023

Moeini, B., Shafii, F., Hidarnia, A., Babaii, G. R., Birashk, B., \& Allahverdipour, H. (2008). Perceived stress, self-efficacy and its relations to psychological well-being status in Iranian male high school students Social Behavior \& Personality: An International Journal, 36(2), 257-266. doi: 10.2224/sbp.2008.36.2.257 
Obermayer, J., Riley, W., Asif, O., \& Jean-Mary, J. (2004). College smoking-cessation using cell phone text messaging. Journal of American College Health, 53(2), 71-78. doi: 10.3200/JACH.53.2.71-78

Ogden, C., Carroll, M., Kit, B., \& Flegal, K. (2014). Prevalence of childhood and adult obesity in the United States, 2011-2012. Jama, 311(8), 806-814. doi:10.1001/jama.2014.732

Sallis, J., Pinski, R., Grossman, R., Patterson,T., \& Nader, P. (1988). The development of selfefficacy scales for health-related diet and exercise behaviors. Health Education Research, 3, 283-292. doi: 10.1093/her/3.3.283

Schwarzer, R., \& Jerusalem, M. (1995). Generalized Self-Efficacy scale. In J. Weinman, S. Wright, \& M. Johnston, Measures in health psychology: A user's portfolio. Causal and control beliefs (pp. 35-37). Windsor, England: NFER-NELSON.

Smith-Jackson, T., \& Reel, J. J. (2012). Freshmen women and the "freshman 15": Perspectives on prevalence and causes of college weight gain. Journal of American College Health, 60(1), 14-20. doi: 10.1080/07448481.2011.555931

Tylka, T., \& Kroon, V. (2013). Intuitive eating scale--2. Journal of Counseling Psychology, 60(1), 137-153. doi:10.1037/a0030893

Wilson, S., Darling, K., Fahrenkamp, A., D'Auria, A., \& Sato, A. (2015). Predictors of emotional eating during adolescents' transition to college: does body mass index moderate the association between stress and emotional eating? Journal of American College Health, 63(3), 163-170. doi:10.1080/07448481.2014.1003374

Wright Decker, J., \& Dennis, K. E. (2013). The eating habits confidence survey: Reliability and validity in overweight and obese postmenopausal women. Journal of Nursing Measurement, 2l(1), 110-119 10p. doi:10.1891/1061.3749.21.1.110 


\section{CHAPTER II}

\section{EXTENDED REVIEW OF THE LITERATURE}

\section{Diet Quality in the US}

Diet quality plays an important role in one's health. Poor diet quality can lead to longterm health complications such as type II diabetes, cardiovascular disease, and some forms of cancer (Murray et al., 2013). Furthermore, increased diet quality has been associated with reduction of chronic disease risk (McCullough et al., 2002). Along with reduced chronic disease risk, higher diet quality has been associated with decreased risk of obesity (Livingstone \& McNaughton, 2016). These finding suggest diet quality can reduce the levels of overweight and obese adults, while also reducing the risk of chronic diseases.

Currently, in the United States, diet quality among adults is improving, but not quickly enough to meet the Healthy People 2020 objectives. According to Wilson et al. (2016), based on the National Health and Nutrition Examination Survey (NHANES), Americans are currently on track to reach the Healthy People 2020 objectives by 2030, ten years later than targeted. While some dietary improvements are being made by the US population, it is estimated Americans will not meet the whole grain goal by 2020 and total vegetable intake has not improved (Wilson et al., 2016). Additionally, there has been an undesirable increase in sodium intake over the past 10 years, is still trending upward, and will most likely not meet the Health People 2020 objective (Wilson et al., 2016). These results are similar to the findings of Krebs-Smith et al. (2010) who evaluated American diets based on the 2001-2004 dietary-recalls collected through NHANES that found that the population did not meet federal recommendations for most groups, but did meet the federal recommendations for total grain, meat, and bean consumption (Krebs-Smith et al., 2010). 


\section{Intuitive Eating}

The term intuitive eating (IE) was coined by registered dietitians Evelyn Tribole and Elyse Resch in 1995 who found calorie restrictive and exchange diets to be ineffective and created IE, an "anti-diet" approach, to combat this issue (Tribole \& Resch, 2013). Tribole and Resch focused on listening to the body's internal hunger and satiety cues. Originally, IE was created for health care professional use, but became popular when Tylka brought IE into the research field, and created a study that examined the overall effectiveness of IE on body image and eating disorders (Tribole \& Resch, 2013). Today, IE has gained recognition and is used by both health care professionals and consumers for weight management (Cadena-Schlam \& LópezGuimerà, 2015; Tylka 2006).

IE is defined as "the dynamic process-integrating attunement of mind, body and food" (Tribole \& Resch, 2012, p. 23). IE is based upon ten principles that each individual should follow for the best results. Table 1 explains each of the ten IE principles (Tribole \& Resch, 2012, pp. 22-29). Much of the IE method is based on becoming aware of physiological signals. IE also focuses on being aware of psychological factors that may impact one's eating behaviors and cause one to ignore physiological signals (Tylka, 2006). The main goal of the IE practice is to focus on listening to the hunger and satiety signals, in hopes that it will prevent overeating, resulting in weight loss (Tribole \& Resch, 2013). These principles emphasize the importance of exercise and food choices too, but physical activity and food choices should be chosen based on what each individual prefers (Tribole \& Resch, 2013).

\section{Mindful Eating versus IE}

Mindful Eating (ME) is similar to IE and has many of same principles as IE. The Center

for Mindful Eating states that ME principles include: being more aware of food choices and of 
thoughts and emotions, paying attention to internal and external environments, feeling free to make choices, and creating balance (Fletcher, n.d.). Many of the ME principles are similar to IE principles in relation to food choices and being aware of one's internal cues, but there are a few differences. ME differs from IE because IE's principles include more guidelines pertaining to emotional eating (Tribole \& Resch, 2013). IE also includes principles that put more emphasis on non-dieting, participating in exercise, and self-resect, while ME does not (Tribole \& Resch, 2013). Overall, both of these eating practices aim for the idea of "normal" eating, and listening to the body's internal hunger and satiety cues.

\section{IE and Body Mass Index (BMI) and Weight Loss}

Several studies have evaluated the effects of IE principles on BMI and weight loss. A cross-sectional study completed by Madden, Leong, Gray, and Horwath (2012) assessed the relationship between IE principles and self-reported BMI. Overall, IE was inversely related to BMI (Madden et al., 2012). Similarly, Hawks, Madanat, Hawks, and Harris (2005) found an inverse relationship between all subscale scores on the IES and BMI. These studies suggest that those with lower BMIs tend to have better IE practices and provide promising evidence that IE may be beneficial in promoting healthy weight maintenance.

A two-and-a-half-year long weight loss intervention was completed using the Health at Every Size (HAES) program, which incorporates IE principles (Bacon, Stern, Van Loan, \& Keim, 2005). Participants were randomly assigned to a diet intervention group or an IE based intervention group, both of which included 24 weekly sessions, each 90 minutes long. The IE group maintained weight and BMI throughout the study and the diet group lost an average of 5.2 percent of their body weight. However, during the follow up, the IE group continued to maintain weight and BMI, while the diet group regained weight. These results suggest that IE may provide 
more long-term weight control than calorie restrictive diets, but more research is needed in order to provide a solid foundation of evidence (Bacon et al., 2005). Additionally, future studies would benefit from intervention with standardized IE materials.

\section{Health Benefits of IE}

A majority of studies evaluating the effectiveness of IE tend to focus on the effects IE has on weight loss (Hawks et. al, 2005; Madden et al., 2012; Tapper et al., 2008), but other studies have examined the effects of IE practice on eating disorders. Research has found that IE intervention is beneficial in treating individuals with eating disorders, specifically binge eating disorder (BED) and anorexia nervosa (Smitham, 2008). This is due to the mental health aspects IE applies during intervention (Goss \& Allan, 2014).

Aside from mental health, IE interventions may impact other health factors. For example, Hawks and colleagues (2005) completed a study examining the effects of IE on several biological factors. Overall it was concluded that high intuitive eaters were healthier compared to low intuitive eaters. Specifically, IE practice was significantly correlated with increased HDL levels, lower triglycerides, and improved cardiovascular risk (Hawks et al., 2005). These studies suggest that there are several other health benefits that IE use can provide besides weight loss, that may not be captured if BMI is the only outcome variable. Not only can desired health indicators be improved, but IE may also be beneficial in treating eating disorders in the clinical setting due to its use of body and mind intervention principles.

\section{IE Practice and Stress Levels}

IE emphasizes the importance of recognizing emotions and feelings before and while consuming foods. Increased stress levels have been linked with emotional eating, which may lead to weight gain (Wilson, Darling, Fahrenkamp, D'Auria, \& Sato, 2015). Among college 
freshmen, it has been found that those who have fewer resources to cope with high stress levels tend to have higher occurrences of emotional eating (Wilson et al., 2015). Research suggests providing IE strategies to college students may be an effective coping mechanism that could prevent the occurrence of emotional eating in college students with high stress levels (Daubenmier et al., 2011). For example, an intervention study found that those who attended nine mindful eating classes had reduced anxiety levels and were less responsive to external food cues, in comparison to the control (Daubenmier et al., 2011). Furthermore, those that increased mindful eating practices had lower cortisol levels indicating that these types of eating practices are related to biological indicators of stress.

Evaluating perceived stress can provide additional information on IE principle use. With increased perceived stress levels, emotional eating can occur. As a result, this may directly affect one's weight status, leading to weight gain. Thus, IE intervention may be an effective method in reducing emotional eating habits in high stressed individuals.

\section{Self-Efficacy and Adherence to IE practice}

Evaluating self-efficacy is an important tool when attempting to understand behavior changes in an intervention. Self-efficacy can be defined as a person's self-perceived ability to handle a situation in the best way possible or necessary (Clark et al., 2014). Evaluating an individual's self-efficacy can help provide information on their own eating behaviors and how they perceive themselves as able to change or maintain certain eating behaviors (Clark et al., 2014). Understanding self-efficacy can provide information on how well someone believes they can adhere to a diet and is useful when long-term studies cannot be conducted.

Increased self-efficacy has been associated with changes in health outcomes. A study completed by Annesi and Gorjala (2010) evaluated the effects of a six-month nutrition and 
exercise intervention that highlighted self-regulatory skills among obese adults. The results showed that following the intervention, self-efficacy for physical activity and controlled eating increased, and this increased self-efficacy was correlated with a decrease in BMI. Therefore, increased self-efficacy may result in desired health behaviors and outcomes (Annesi \& Gorjala, 2010).

\section{Texting Intervention Programs}

Texting intervention has been seen to be a successful platform for behavior change and nutrition education focused intervention (Bauer et al., 2010; Brown, O'Connor, and Salvaiano, 2014; Obermayer, Riley, Asif, \& Jean-Mary, 2004). A commonality found among most studies is that texting is the preferred intervention platform among participants. Forty-eight percent of the college aged participants from the MyPlate texting intervention study, completed by Brown et al. (2014), reported that text messages were a good way to receive health information, followed by Facebook. Results of the smoking cessation texting program also showed college-aged participants were more willing to complete a texting based intervention program due to not having to attend a formal or professional program (Obermayer et. al, 2004). These students within the smoking cessation program also reported that they were more likely to adhere to intervention through automated text message reminders, instead of having to motivate themselves to seek information, such as opening an email or logging into a website (Obermayer et. al, 2004). In a similar study that included nutrition education through texting, it was also found participants were more likely to participate in the study when face-to-face intervention was not involved (Bauar et al., 2010). Not only have nutrition text messaging intervention programs been successful, but they are a non-costly form of intervention that reaches a large group of people (Brown et al., 2014). 
In addition, several studies have shown that the use of text messages is an effective intervention method for changing health behaviors (Bauer et al., 2010; Brown, O’Connor, and Salvaiano, 2014; de Niet et al., 2012; Hebden et al., 2014; Obermayer, Riley, Asif, \& Jean-Mary, 2004). Although studies varied in specific intervention methods, each intervention involved a texting component.

Two studies aimed at decreasing BMI among obese children. Both of these studies included three months of texting intervention, and were minimally successful. One study found no significant difference in BMI between the texting and in-person intervention groups (de Niet et al., 2012), while another study found a small BMI decrease from pre- to post-texting intervention (Bauer et al., 2010). These studies differed in how the text messages were used, however. In the study by de Niet et al. (2012) text messages were individualized based upon selfreported health behaviors, while the study by Bauer et al. (2010) used texting as a way for participants to report health behaviors only. The results from the study conducted by Brauer et al. suggest including self-reported health behaviors through a texting program may decrease BMI levels (2010).

A smoking cessation study, completed by Obermayer et al. (2004), examined the effectiveness of an automated and tailored text messaging intervention program among college students. There was also an optional website that was used for tracking cigarettes per day and text message history (Obermayer et al., 2004). After six months, the program was found to have significantly improved smoking cessation rates. Although there was no control group in this study, the study showed intervention was associated with a decrease in cessation rates. This study provides evidence that behavior modification can be achieved in the college population through texting intervention. 
Food behaviors have also been improved after the implementation of texting intervention among college students. Two pilot studies found that increased vegetable consumption occurred after a texting intervention in comparison to the control (Brown et al., 2014; Hebden et al., 2014). Additionally, these interventions also found an increase in exercise activity, a decrease in sugar sweetened beverage consumption, and an average of 5.7 pounds lost (Hebden et al., 2014) and an increase in fruit consumption (Brown et al., 2014).

Although both were successful, the two pilot studies differed in design. The Hebden et al. (2014) study included a control and texting intervention group, in which both groups were provided a printed booklet that included information on recommended amounts of physical activity, servings of food groups, and meal plans. The intervention group was then enrolled in a 12-week text messaging and email program. The study by Brown et al. (2014) utilized a control group with a mailed handout, and the intervention period was only seven weeks in duration, with participants receiving one text each week. These studies indicate that behavior change is possible through a short, text-messaging platform, although further studies need to be conducted with control or comparison groups.

Currently, no studies to date have been found that evaluate the success and effectiveness of using text messaging as a platform for IE intervention. The results from these studies suggest that text messaging programs can be a successful intervention method for college students. Texting is a cost effective way to reach multiple participants, but is also easy to use for the participants. The ease of use and non in-person intervention may increase participation, as well. Although these studies provide evidence that texting is a successful intervention method, there are minimal long-term studies that follow-up with participants post intervention. 
Despite minimal long-term studies and cohesive texting intervention methods between these studies, it is believed that conducting a study that evaluates the success and effectiveness of an IE intervention program through text messaging can further advance IE intervention methods in college students. This study will evaluate if text messaging is an effective IE intervention method for the college population. 


\section{References}

Annesi, J., \& Gorjala, S. (2010). Relations of self-regulation and self-efficacy for exercise and eating and BMI change: A field investigation. Biopsychosocial Medicine, 4(1), 10. doi: $10.1186 / 1751-0759-4-10$

Bacon, L., Stern, J. S., Van Loan, M. D., \& Keim, N. L. (2005). Research: Size acceptance and intuitive eating improve health for obese, female chronic dieters. Journal of The American Dietetic Association, 105(6), 929-936. doi:10.1016/j.jada.2005.03.011

Bauer, S., de Niet, J., Timman, R., \& Kordy, H. (2010). Enhancement of care through selfmonitoring and tailored feedback via text messaging and their use in the treatment of childhood overweight. Patient Education and Counseling, 79, 315-319. doi:

10.1016/j.pec.2010.03.014

Brown, O. N., O'Connor, L., \& Savaiano, D. (2014). Mobile MyPlate: A pilot study using text messaging to provide nutrition education and promote better dietary choices in college students. Journal of American College Health, 62(5), 320-227. doi:

10.1080/07448481.2014.899233.

Cadena-Schlam, L., \& López-Guimerà, G. (2015). Intuitive eating: An emerging approach to eating behavior. Nutricion Hospitalaria, 31(3), 995-1002. doi: 10.3305/nh.2015.31.3.7980

Clark, M., Abrams, D., Niaura, R., Eaton, C., Rossi, J. (2014). Weight efficacy life-style questionnaire. International Journal of Clinical and Health Psychology, 14(1), 1-8. doi: 10.1007/978-981-287-087-2_3-1

Daubenmier, J, Kristeller, J., Hecht, F., Maninger, N., Kuwata, M., Jhaveri, K., Lustig, H., Kemeny, M., Karan, L., \& Epel, E. (2011). Mindfulness intervention for stress eating to 
reduce cortisol and abdominal fat among overweight and obese women: an exploratory randomized controlled study. Journal of Obesity, 2011(1), 1-13, doi:10.1155/2011/651936

de Niet, J., Timman, R., Bauer, S., van den Akker, E., de Klerk, C., Kordy, H., Passchier, J. (2012). Short message service reduces dropout in childhood obesity treatment: A randomized controlled trial. Health Psychology, 31(6), 797-805. doi: 10.1037/a0027498

Fletcher, M. (n.d). The principles of mindful eating. The Center for Mindful Eating. Retrieved October 21, 2015.

Goss, K., \& Allan, S. (2014). The development and application of compassion-focused therapy for eating disorders. British Journal of Clinical Psychology, 53(1), 62-77. doi:10.1111/bjc.12039

Hawks, S., Madanat, H., Hawks, J., \& Harris, A. (2005). The relationship between intuitive eating and health indicators among college women. American Journal of Health Education, 36(6), 331-336. doi:10.1080/19325037.2005.10608206

Hebden, L., Cook, A., Ploeg, H. P., King, L., Bauman, A., \& Allman-Farinelli, M. (2014). A mobile health intervention for weight management among young adults: A pilot randomized controlled trial. Journal of Human Nutrition \& Dietetics, 27(4), 322-332. doi:10.1111/jhn. 12155

Krebs-Smith, S., Guenther, P., Subar, A. F., Kirkpatrick, S., \& Dodd, K. (2010). Americans Do Not Meet Federal Dietary Recommendations. The Journal of Nutrition, 140(10), 18321838. http://doi.org/10.3945/jn.110.124826

Livingstone, K. M., \& McNaughton, S. A. (2016). Diet quality is associated with obesity and hypertension in Australian adults: a cross sectional study. BMC Public Health, 16, 161-10. doi:10.1186/s12889-016-3714-5 
Madden, C., Leong, S., Gray, A., \& Horwath, C. (2012). Eating in response to hunger and satiety signals is related to BMI in a nationwide sample of 1601 mid-age New Zealand women. Public Health Nutrition, 15(12), 2272-2279. doi:10.1017/S1368980012000882

McCullough, M, Feskanich, D., Stampfer, M. , Giovannucci, E., Rimm, E., Hu, F., \& Willett, W. (2002). Diet quality and major chronic disease risk in men and women: moving toward improved dietary guidance. American Journal of Clinical Nutrition, 76(6), 1261.

Murray, C., Abraham, J., Ali, M., Alvarado, M., Atkinson, C., Baddour, L., \& Lopez, A. (2013). The State of US Health, 1990-2010 Burden of Diseases, Injuries, and Risk Factors. JamaJournal of The American Medical Association, 310(6), 591-608. doi:

10.1001/jama.2013.13805

Obermayer, J., Riley, W., Asif, O., \& Jean-Mary, J. (2004). College smoking-cessation using cell phone text messaging. Journal of American College Health, 53(2), 71-78. doi: 10.3200/JACH.53.2.71-78

Smitham, L. (2008). Evaluating an intuitive eating program for binge eating disorder: A benchmarking study [dissertation]. South Bend, IN: University of Notre Dame.

Tapper, K., Shaw, C., Ilsley, J., Hill, A., Bond, F., \& Moore, L. (2009). Exploratory randomized controlled trial of a mindfulness-based weight loss intervention for women. Appetite, 52(2), 396-404. doi: 10.1016/j.appet.2008.11.012

Tylka, T. (2006). Development and psychometric evaluation of a measure of intuitive eating. Journal of Counseling Psychology, 53(2), 226-240. doi: 10.1037/00220167.53.2.226

Tribole, E., \& Resch, E. (2012). Intuitive eating. New York: St. Martin's Griffin, 2012. Tribole, E., \& Resch, E. (2013). Intuitive eating. Retrieved from http://www.intuitiveeating.org 
Wilson, M. M., Reedy, J., \& Krebs-Smith, S. M. (2016). Research: American Diet Quality: Where It Is, Where It Is Heading, and What It Could Be. Journal Of The Academy Of Nutrition And Dietetics, 116, 302-310.e1. doi:10.1016/j.jand.2015.09.020

Wilson, S., Darling, K., Fahrenkamp, A., D'Auria, A., \& Sato, A. (2015). Predictors of emotional eating during adolescents' transition to college: does body mass index moderate the association between stress and emotional eating? Journal of American College Health, 63(3), 163-170. doi:10.1080/07448481.2014.1003374 


\section{APPENDIX A: HEALTHY EATING BEHAVIORS HANDOUT}

\section{Healthy Behaviors to Practice}

Forget all methods of dieting today! Focus on listening to what your body is telling you.

2 Ask yourself before eating today, is your body telling you it's hungry? You may be experiencing a behavior or emotion urging you to eat, and no actual hunger. 3 Sometimes our bodies crave sweet treats. Remind yourself that it is okay to enjoy your
favorite foods in moderation.

4 Remember: There are no good or bad foods! Aim for a well-balanced diet.

5 Feel your fullness: Listen to the internal body signals of hunger and fullness.

6 Sit down and enjoy your dinner today. Turn off the television and focus on the meal you are eating without distractions.

7 Feeling stressed or upset? Eating when you are not hungry will not help you manage your emotions. Respect and love yourself. Remember you are different from all others and you should
appreciate your genetic makeup!

Q Get out and exercise today! Whether it is an extra-long walk or perhaps a new fitness class at the gym - your body will thank you for it.

1 Honor your health - choose foods that make you feel good and taste good 


\section{APPENDIX B: RECRUITMENT EMAIL}

Subject Line:

Eating Behaviors Study

\section{Message:}

Dear Prospective Participant,

You are receiving this email because you have been invited to participate in a study, titled "Effectiveness of Healthy Eating Behavior Intervention through Text Messages and Email." The purpose of this study is to evaluate the overall effectiveness of delivering a healthy eating behavior intervention program through text messages and email. The results of this study can help determine if interventions through text messaging or email can improve eating habits among college students.

You will be asked to complete 2 online surveys. Survey \#1 before the program begins, and Survey \#2 after the program has completed. You will be asked to provide your cell phone number and email. Your cell phone number will be needed in order to receive text messages related to healthy eating behaviors. You will either be assigned to the email intervention program or texting intervention program. The email group will receive one intervention email. The text messaging group will receive two text messages per week for a duration of 5 weeks that will be sent Monday through Saturday between 10 am and 6:30 pm. Standard text messaging rates will apply. The 2 online surveys will be completed. One before the first text message is received and one after the last text message is received. Each survey will take approximately 15 minutes to complete.

To participate you must be at least 18 years of age to 24 years old. All participants need to live within a 15 minute walking distance to campus. In addition, you must and have access to a smart phone device. Your participation in this survey will contribute to the body of knowledge relating to nutrition text messaging and email programs and healthy eating behaviors in college students. Participants who complete the first and second survey will be entered to win one of four $\$ 25$ Amazon gift card delivered via email.

If you are eligible for this study and are interested in completing the surveys and text messaging program, please click the link below:

$<$ Insert Link $>$

Thank you for your time and consideration.

Sincerely, 


\title{
APPENDIX C: INFORMED CONSENT
}

\author{
Informed Consent to Participate in Research
}

You are receiving this email because you are invited to participate in a study, titled "Effectiveness of Healthy Eating Behavior Intervention through Text Messages and Email."

To participate in this study, you must be a college student and at least 18 years old to 24 years old and live within a 15-minute walking distance to campus. Your participation in this survey will contribute to the body of knowledge relating to nutrition email and text messaging programs.

The purpose of this study is to evaluate the overall effectiveness of a nutrition related email and text messaging intervention program for college students. The results of this study can help determine if an intervention through text messaging and email can improve eating habits and nutrition is a successful platform for the college student population.

If you agree to take part in this study you will be a part of a text-messaging program or email program. The email group will receive one healthy eating behavior intervention email. The texting group will receive healthy eating behavior related text messages for 5 weeks, two times per week, or 10 messages total. Additionally, you will be asked to complete 2 online surveys at 2 different time points. You will be asked to complete the first survey before any text messages or emails are sent. This survey will take you approximately 20 minutes. You will then be asked to take the second survey 5 weeks after the first email or text is sent. This survey will also take you 20 minutes.

There are very minimal risks associated with this study and are no greater than those that occur in daily life. You may feel some discomfort in answering some of the questions, but with the online format of the survey, we hope any discomfort is minimized. Loss of confidentiality is always a risk. The following procedures will be used to protect confidentiality of the data collected from you: You will be assigned an Identification number based on your phone number and will be kept during the survey collection phases for tracking purposes only. No names will be used or recorded during the study. All responses will be stored on a password protected computer. Only members of the research staff will have access to the passwords. Participants' identities will be protected and participation is voluntary. Participants can withdraw from the study at any time. You may withdrawal from the survey by selecting EXIT or by closing the browser. You may withdraw from the text messaging program by texting STOP. You may withdraw from the email intervention at any time by emailing the recruiter of this study. There are no consequences if you decide to withdraw at any point.

There are no costs to you to complete the intervention or surveys. Participants who complete both surveys will be entered to win one of four \$25 Amazon gift cards via email. After you complete the second survey, you can click a link that will direct you to a separate webpage where we will need to collect your name, email address, and mailing address. This information is only being collected for purposes of distributing the gift card; it will not be linked to your survey responses or retained for other purposes. Please note that compensation for participation in research may be taxable. 
Take as long as you like before you make a decision. If you have any questions, you may contact the principal investigator or the co-principal investigator. If you have questions regarding your rights or if you are dissatisfied with this study, you may anonymously contact the Research Ethics \& Compliance Office. This study has been approved by the Illinois State University Institutional Review Board.

By clicking agree, you are indicating that you are consenting to participate in this research.

$\square$ Agree, I do wish to participate, I am over 18, and I am a college student at Illinois State University.

$\square$ Disagree, I do not wish to participate 